\title{
Evolución de la Ley de Directrices y Bases de la Ley de Educación Nacional Law - no 5.692/1971 la enfermería profesional en Brasil
}

\section{Developments of the Guidelines and Bases for National Education Law $-n^{\circ} 5.692 / 1971$ in nursery teaching at a professional level in Brazil}

\section{Desdobramentos da Lei de Diretrizes e Bases da Educação Nacional, Lei no 5.692/71, no ensino profissionalizante em enfermagem no Brasil}

Marta Motter Magri ${ }^{1}$, Genival Fernandes de Freitas ${ }^{2}$

${ }^{1}$ Aluna do Programa de Pós-Graduação em Gerenciamento em Enfermagem da Escola de Enfermagem da USP. Enfermeira do Hospital Universitário da Universidade de São Paulo.

${ }^{2}$ Professor Associado do Departamento de Orientação Profissional da Escola de Enfermagem da USP. Orientador do trabalho objeto da presente investigação.

Cómo citar este artículo en edición digital: Motter Magri, M; Fernandes de Freitas, G. (2013) Desdobramentos da Lei de Diretrizes e Bases da Educação Nacional, Lei no 5.692/71, no ensino profissionalizante em enfermagem no Brasil. Cultura de los Cuidados.17, 37. Disponible en: <http://dx.doi.org/10.7184/cuid.2013.37.05>

Correspondencia: , Escola de Enfermagem da Universidade de São Paulo, Av. Dr. Enéas de Carvalho Aguiar, 419 - 05403-000 São Paulo - SP. Correo electrónico: marmagri@gmail.com. Teléfono: 5511989248960 - 551146202842

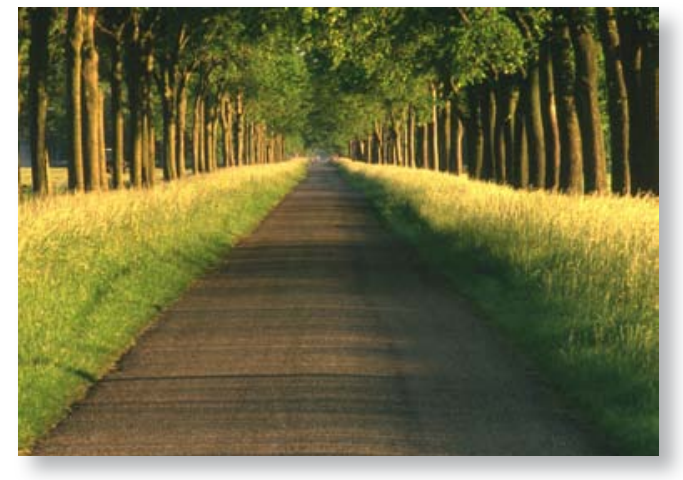

\section{ABSTRACT}

The guarantee of historical memory of the level education in nursing, in the 1970s, was the object of this investigation. This study aimed to describe and analyze the socio-political and historical circumstances in which Law no. 5,692, of August 12, 1971, about Guidelines and Bases of National Education was promulgated, and discuss the changes and developments of this teaching professional nursing. This is a descriptive study, qualitative, exploratory and social-historical nature, based on documentary analysis. We opted for the Micro-history to give support to the theoretical discussion of the results of this investigation as analyzing historical documents from the perspective that, although you can not see the entire society from a social sni-ppet, you can see something of the reality social involving human fragment examined. The delimitation of the historical sources of the study includes the Collection of the Historical Archives of the Brazilian Nursing Association - São Paulo Section (ABEn/SP), the Collection of documents on the ABEn / SP, in the Central Cultural History of Iberian-American, of the School of Nursing of University of São Paulo and Series Documents of the Ministry of Education and Culture. From this LDB no. 5.692/71, the nursing education was fully integrated into the national system of education and its enactment occurred during the 
military dictatorship and the ideology of the "economic miracle." According to this ideology, the Brazilian educational system should suit the developmental economic model, with personnel training at the technical level, to increase and cheapen human resources to work. The ABEn/SP, as a representative body of the political and ideological interests of professionals, led discussions on the issues of human resources training in nursing, and in the 70's more than half the number of nursing was mostly without special training. Also due to this fact, there were government initiatives to try to reverse this situation. Despite the issues of nursing education they are not explicit in the text of the LDB No. 5.692/71, the results of this study revealed that the legislation had studied developments in policy decisions in the context of vocational education and consequently impacted on the training of nursing.

Keywords: History of Nursing; Nursing Education; Nursing Legislation.

\section{RESUMEN}

La garantía de la memoria histórica de la enseñanza a nivel medio de la formación profesional en enfermería, en la década de 1970, fue el objeto de esta investigación. Tuvo como objetivos describir y analizar las circunstancias socio-políticas e históricas en que la Ley $\mathrm{N}^{\circ}$ 5692, de 12 de agosto de 1971, Directrices y Bases de la Educación Nacional fue promulgada, bien como discutir los cambios y la evolución de esta enseñanza en enfermería profesional. Se trata de un estudio descriptivo, cualitativo, exploratorio y de naturaleza histórico-social, basado en el análisis documental. Se optó por la Micro-historia para dar apoyo a la discusión teórica de los resultados de esta investigación, pues el análisis de documentos históricos, desde el punto de vista de que mientras no sea posible veer la sociedad entera a partir de un fragmento social, es posible veer algo de la realidad social que envuelve el fragmento humano investigado. Así, la delimitación de las fuentes históricas del estudio incluye la colección de los Archivos Históricos de la Asociación Brasileña de Enfermería - Sección São Paulo, la Colección de documentos sobre la ABEn / SP, existente en el Centro Histórico Cultural de la Enfermería Ibero Americana y las Series de Documentos del Ministerio de Educación y Cultura. A partir de esta LDB No. 5.692/71, la educación de enfermería se integró plenamente en el sistema nacional de educación y su promulgación se produjo durante la dictadura militar y la ideología del "milagro económico”. Según esta ideología, el sistema educativo brasileño debería adaptarse al modelo económico de desarrollo, con la capacitación del personal a nivel técnico, para aumentar y abaratar los recursos humanos para trabajar. A ABEn, como órgano de representación de los intereses políticos e ideológicos de los profesionales de enfermería, dirigió los debates sobre las cuestiones de la formación de recursos humanos en esa area, siendo que en los años 70 más de la mitad del número de personal de enfermería estaba prácticamente sin formación específica. También debido a este hecho, hubo iniciativas del gobierno para tratar de revertir esta situación. A pesar de los problemas de la educación en enfermería que no están explícitos en el texto de la LDB N o 5.692/71, los resultados de este estudio revelaron que la legislación estudiada tuvo desdoblamientos en las decisiones políticas en el ámbito de la enseñanza profesional y, por consiguiente impactó en la formación de enfermería.

Palabras clave: Historia de la Enfermería; Educación en Enfermería; Legislación de Enfermería. 


\section{RESUMO}

A garantia da memória histórica do ensino em nível profissionalizante em enfermagem, na década de 1970, foi o objeto dessa investigação. Teve como objetivos descrever e analisar o contexto sócio-político e as circunstâncias históricas em que a Lei no 5.692 , de 12 de agosto de 1971, das Diretrizes e Bases da Educação Nacional, foi promulgada, bem como discutir as mudanças e desdobramentos dessa no ensino profissionalizante em enfermagem. Trata-se de estudo descritivo, qualitativo, exploratório e de natureza histórico-social, com base em análise documental. Optou-se pela Micro-história para dar sustentação teórica à discussão dos resultados dessa investigação, pois a análise dos documentos históricos, sob o prisma de que, embora não seja possível enxergar a sociedade inteira a partir de um fragmento social, é possível enxergar algo da realidade social que envolve o fragmento humano examinado. A delimitação das fontes históricas do estudo compreende o Acervo do Arquivo Histórico da Associação Brasileira de Enfermagem - Seção São Paulo; o Acervo documental sobre a ABEn/SP, existente no Centro Histórico Cultural da Enfermagem Ibero-Americana da Escola de Enfermagem da USP e a Série Documenta do Ministério da Educação e Cultura. A partir dessa LDB no 5.692/71, o ensino de Enfermagem foi totalmente integrado ao sistema nacional de Educação e sua promulgação ocorreu durante a Ditadura Militar e a ideologia do "milagre econômico". De acordo com essa ideologia, o sistema educacional brasileiro deveria adequar-se ao modelo econômico desenvolvimentista, com treinamento de pessoal de nível técnico, visando aumentar e baratear os recursos humanos para o trabalho. A ABEn, como entidade representativa dos interesses políticos e ideológicos dos profissionais da área, liderava os debates sobre as questões da formação dos recursos humanos na enfermagem, sendo que na década de 70 mais da metade do contingente de enfermagem era majoritariamente sem formação específica. Também por conta dessa realidade, houve iniciativas governamentais para tentar reverter essa situação. Apesar das questões do ensino da enfermagem não se encontrarem explicitadas no texto da LDB no 5.692/71, os resultados deste trabalho revelaram que a legislação estudada teve desdobramentos nas decisões políticas no âmbito do ensino profissionalizante e, consequentemente, impactou sobre a formação dos profissionais de enfermagem.

Palavras-chave: História da Enfermagem; Educação em Enfermagem; Legislação de Enfermagem

\section{INTRODUÇÃO}

O presente estudo tem como foco a Lei de Diretrizes e Bases da Educação Nacional no 5.692, de 12 de agosto de 1971 e os possíveis desdobramentos dessa legislação na formação, em nível médio profissionalizante, em enfermagem.

Para os profissionais que lidam com o ensino nesta modalidade, por um longo período de tempo, não era clara a legislação que regulava a formação e o exercício profissional de nível médio em enfermagem, fato observado também por Aguilar e Dantas (1999) e Caverni (2005). Desta maneira, foi analisada a Lei no 5.692, de 12 de agosto de 1971, das Diretrizes e Bases da Educação Nacional, com enfoque nas modificações que trouxe para o ensino profissionalizante em enfermagem, e tem como objeto os impactos e desdobramentos dessa legislação na formação profissionalizante nas escolas de Enfermagem, bem como no pro- 


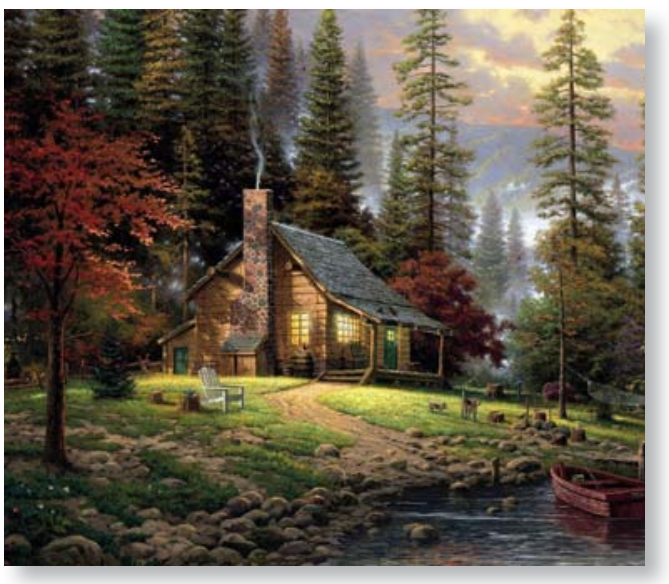

cesso de desenvolvimento da enfermagem na sociedade brasileira.

Como afirmam Aguilar e Dantas (1999), a Legislação Educacional no Brasil prevê e estabelece normas e critérios que norteiam tanto a educação geral quanto a formação profissional. Segundo esses autores, a formação profissional na área de enfermagem, atualmente, é definida pelo sistema educacional, como de nível médio, (habilitações profissionais) ou ensino superior. A expectativa quanto ao ensino de nível médio em enfermagem, em seus primórdios, seria a formação em número suficiente para substituir a grande massa sem preparo formal para o trabalho que atuava em diversas partes do país.

A enfermagem brasileira, ao longo de sua história, teve um contingente significativo de mão de obra não qualificada, ou seja, sem preparo formal. As mudanças na qualidade do ensino e preparo educacional na assistência de enfermagem foram estruturadas a partir de 1930. A partir de 1940, a área da saúde teve grande destaque e crescimento devido à conquista pelos trabalhadores de direitos sociais dentro da sociedade industrial. Cada vez mais era necessária a capacitação de mão de obra qualificada para assumir os cuidados de uma assistência voltada ao modelo hospitalar.
Nesse contexto, era necessário um número maior de pessoal auxiliar, pois as enfermeiras eram convocadas a assumir as atividades administrativas, em um modelo de saúde individualizada e hospitalocêntrica (Aguilar, Dantas, 1999).

A primeira legislação que organizou o ensino de enfermagem em nível nacional (abrangendo o nível superior e médio) foi a Lei Federal no 775, de 06 de agosto de 1949. Apesar dos esforços para ser implantado no Brasil o modelo anglo-americano de enfermagem, através desta legislação foi oficializado o curso de auxiliar de enfermagem, criando uma categoria parcialmente habilitada para executar atividades de enfermagem. Esta foi, portanto, a legislação educacional vigente até 1961 (Santos et al., 2002).

A nova Constituição brasileira foi promulgada em 18 de setembro de 1946 . O projeto da Lei de Diretrizes e Bases da Educação Nacional elaborado já era uma exigência da Constituição Federal de 1946, a qual determinava caber à União sua fixação. O anteprojeto da lei, de início, foi encaminhado à Câmara Federal, em 1948. Porém, entre emendas e engavetamentos e substitutos, só viria a se tornar lei em 1961 (Fausto, 1995).

A LDB no 4.024/61 previa uma descentralização burocrática do ensino, criando, entre outras coisas, um órgão colegiado denominado Conselho Federal de Educação (CFE), que estabelecia os currículos mínimos dos cursos de ensino superior e médio. O CFE publicava periodicamente a revista Documenta, onde eram registrados todos os pronunciamentos, pareceres e legislação geral complementar, para a administração da educação no nível federal. Amparado por essa prerrogativa, foi promulgado em 1961 o Decreto no 50.837, que regulamentou a Lei no 2.604, de 17 de se- 
tembro de 1955, quase seis anos após sua promulgação, definindo todas as categorias que poderiam exercer legalmente a enfermagem (Monteiro, 2009; Oguisso, 2002).

O nível técnico de enfermagem surgiu na década de 1960 como uma proposta governamental em parceria com a entidade representativa da enfermagem, ABEn. As funções de supervisão de pequenas unidades e de cuidados de doentes graves que não eram atendidos satisfatoriamente nem por auxiliares, por falta de preparo, e nem por enfermeiros, devido a seu reduzido número, levou a Associação Brasileira de Enfermagem (ABEn) a solicitar ao CFE, em 1965, a regulamentação do Curso Técnico de Enfermagem. (Lima, Apollinário, 2011; Oguisso, 1977).

Na década de 70, sabe-se que as entidades governamentais, preocupadas com o pessoal do setor de saúde, pois havia grande contingente inadequadamente despreparado, foram firmados diversos acordos entre o Brasil e a Organização Pan-americana de Saúde (OPAS). Desta maneira foram criadas e viabilizadas as estratégias que apoiariam o desenvolvimento de processos de qualificação profissional (Oguisso, 2002).

Até a promulgação da LDB no 5.692/71, a Enfermagem apresentava características próprias e não era vinculada ao sistema de ensino no país. A partir dessa legislação, o ensino de Enfermagem foi totalmente integrado ao Sistema de Ensino Nacional.

Assim, os objetivos da presente investigação foram descrever e analisar o contexto sócio-político e as circunstâncias históricas em que a Lei no 5.692, de 12 de agosto de 1971, das Diretrizes e Bases da Educação Nacional, foi promulgada; bem como discutir mudanças e desdobramentos dessa legislação no ensino profissionalizante em enfermagem.

\section{REFERENCIAL TEÓRICO-METODOLÓ- GICO DO ESTUDO}

Trata-se de um estudo descritivo, qualitativo, exploratório, de natureza histórico-social, com base em análise documental. A pesquisa documental qualitativa é feita a análise do conteúdo de um texto, em busca de significados, patentes ou ocultos, para interpretar a intencionalidade da construção do texto, valores e intenções do autor, além do contexto sociocultural do produtor da mensagem, que devem ser analisados como produto da sociedade que os fabricou, influenciados pelas forças ideológicas dominantes no poder, na época de sua construção (Chizzotti, 2010; Porto, Freitas, González, 2009).

Neste estudo foram utilizadas como fontes as Legislações de ensino; atas das reuniões da Associação Brasileira de Enfermagem seção São Paulo (ABEn/SP) que tinham relação com o objeto de pesquisa; Anais da Revista Brasileira de Enfermagem; acervo documental sobre a ABEn/SP localizado no Centro Histórico Cultural da Enfermagem Ibero-Americana da Escola de Enfermagem da Universidade de São Paulo (CHCEIA/EEUSP); e a série Documenta do Ministério da Educação e Cultura (MEC). Optou-se pela técnica da micro-história para fundamentar a análise dos resultados dessa investigação, porque esta possibilita um olhar mais aprofundado sobre o objeto do estudo, contextualizando os impactos e desdobramentos possíveis da legislação estudada, analisando melhor os contextos sociopolíticos e econômicos da época. Assim, o referencial da micro-história é um suporte para discutir esses impactos da LDB no 5.692/71 para o ensino profissionalizante da enfermagem, tendo em vista uma política educacional como uma das metas da ABEn/SP. A Micro-história, como um desdobramento do pensar, amplia 
o significado dos documentos, "rompe com a antiga ideia que dotava os textos e as obras de um sentido intrínseco, absoluto e único" (Chartier, 1990, p. 37).

Para Revel (1998), a micro-história se propõe enriquecer a análise social, tentando compreender como pequenos detalhes individuais dão acesso às lógicas de grupo. Desta maneira a definição da escala de análise é essencial para este método. Este autor ainda afirma que a escolha da escala particular de observação não consiste apenas em “(...) representar a realidade constante em tamanho maior ou menor, e sim transformar o conteúdo da representação (ou seja, a escolha daquilo que é representável).” (p. 20). Desta maneira, a variação de escala permite ao investigador passar de uma história para outra. Assim, levou-se em consideração, para a seleção de documentos selecionados para a análise, não somente os de relevância para a legislação desse estudo, mas os que nos permitem visualizar a lógica política do recorte histórico.

Em suma, optou-se pela Micro-história como ferramenta para dar sustentação teórica à discussão dos resultados dessa investigação, pois analisando os documentos históricos sob o prisma de que, embora não seja possível enxergar a sociedade inteira a partir de um fragmento social, é possível enxergar algo da realidade social que envolve o fragmento humano examinado.

Quanto aos locais de coleta de dados, cabe pontuar que a delimitação das fontes históricas do estudo compreende o Acervo do Arquivo Histórico da Associação Brasileira de Enfermagem - Seção São Paulo; o Acervo documental sobre a ABEn/SP, existente no Centro Histórico Cultural da Enfermagem Ibero-Americana da Escola de Enfermagem da USP e a Série Documenta do Ministério da Educação e Cultura.

\section{RESULTADOS}

A primeira legislação que regulou o ensino em nível técnico no Brasil foi o Decreto $n^{\circ}$ 16.300 de 1923, que aprovou o regulamento do Departamento Nacional de Saúde Pública (DNSP), com as normas de ensino da enfermagem na Escola anexa ao Hospital Geral de Assistência do DNSP, posteriormente chamada de Escola de Enfermagem Anna Nery.

A Lei no 775, de 06 de agosto de 1949, que dispunha sobre o ensino de enfermagem no país, trouxe reconhecimento legal a estes cursos, determinando requisitos mínimos para sua organização e funcionamento. A duração era de dezoito meses e tinha como requisitos que os participantes deveriam possuir o curso primário concluído ou aprovação no exame de admissão do $1^{\circ}$ ano ginasial ou aprovação no exame de habilitação que a escola determinasse. A idade mínima era de 16 anos para matrícula, com atestado de idoneidade moral, sanidade física e mental e de vacinação (Oguisso, 2002).

É importante observar que foram quase 13 anos para a consolidação do processo legislativo da primeira Lei de Diretrizes e Bases, de 1961, com início da sua discussão em 1948. Assim, a Lei no 4.024, de 20 de dezembro de 1961, estabelecia que o ensino médio seria ministrado em dois ciclos: o ginasial e o colegial, e abrangeria, entre outros, os cursos secundários, técnicos e de formação de professores. A regulação dos cursos de nível médio em enfermagem seria feita pelos Conselhos de Educação, nas esferas estaduais e federais, como disposto nesta mesma legislação, em seu parágrafo único, do art. 47: “Os cursos técnicos de nível médio não especificados nesta lei serão regulamentados nos diferentes sistemas de ensino" (Monteiro, 2009).

Através do Parecer no 279/62 do CFE, de 11 de novembro de 1962, as Escolas de Au- 
xiliares de Enfermagem foram classificadas como de nível médio, além de delegar para a esfera estadual a competência de sua criação e autorização. Neste mesmo parecer foi sugerida a criação das "Escolas médias de Enfermagem" com exigência do curso ginasial completo. Esta mesma indicação seria aprovada pelo CFE em 1964, estabelecendo normas básicas para a constituição do curso que foram concretizadas através dos Pareceres no 129/64 e no 89/64(Brasil, 1974).

Através da Portaria Ministerial no 106/65 estabeleceu-se o currículo mínimo do curso de auxiliar de enfermagem, levando em conta os pareceres do CFE acima citados. Desta maneira, houve a regulamentação do curso de auxiliar de enfermagem no Sistema Federal de Ensino e o mesmo foi fixado como curso ao nível de $2^{\circ}$ ciclo, porém sem a exigência da $1^{\mathrm{a}} \mathrm{e}$ $2^{a}$ séries do nível ginasial como pré-requisitos. Algumas escolas poderiam se dedicar à formação específica do auxiliar de enfermagem, desde que o candidato tivesse o certificado de aprovação nas cinco disciplinas gerais. A duração do curso era de dois anos letivos, de 180 dias e a idade mínima para ingresso no curso seria de 16 anos (Santos, 1997).

Pelo Parecer no 171/66, de 11 de março de 1966, do CFE, foi aprovado o primeiro Curso Técnico de Enfermagem no Sistema Federal a ser instalado na Escola de Enfermagem Anna Nery, com grade curricular expressa e pré-requisitos específicos (Brasil, 1974). Para o Estado de São Paulo, a Resolução no 45/66, de 05 de dezembro de 1966, definiu o tempo de duração do curso de técnico de enfermagem, fixando-o em três anos, além de instituir as disciplinas obrigatórias9 e as disciplinas específicas10. Os estágios eram obrigatórios a partir do segundo semestre, em todas as disciplinas específicas do currículo adotado (Mon-

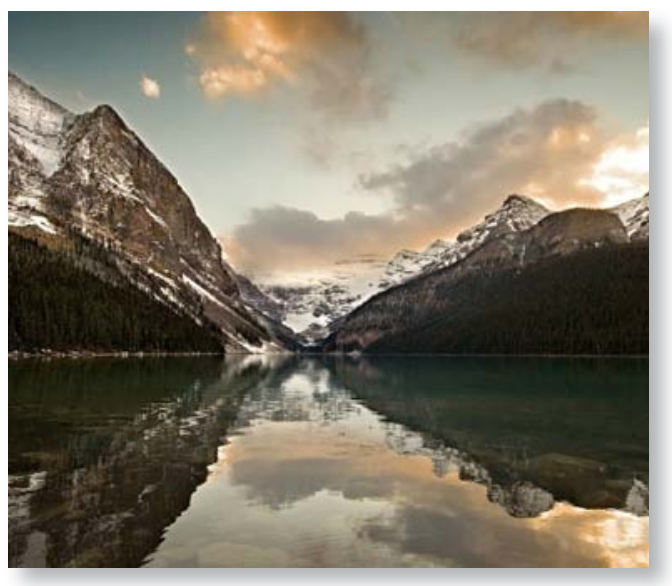

teiro, 1979). Em 1968, foi definido no sistema de ensino do Estado de São Paulo o Curso de Aprendizagem de Enfermagem, que formaria os auxiliares de enfermagem, através da Resolução do CEE no 4/68. Nesta resolução eram estabelecidas a duração de duas séries anuais, com disciplinas do primeiro ciclo do ensino médio, disciplinas específicas do ensino técnico e práticas educativas. A idade mínima de 16 anos para o ingresso era condição para o curso, além do certificado de conclusão do curso primário. Nesta Resolução também eram fixadas as disciplinas obrigatórias e a obrigatoriedade dos estágios com um mínimo de 200 horas (Monteiro, 1979).

Em 10 de janeiro de 1970, foi emitido o Parecer no 75/70 da Câmara de ensino primário e médio, com título de "Normas para cursos de auxiliar de enfermagem". Neste Parecer era exposta a situação da área de saúde naquela década de 70, com diferenças extremas entre regiões e distribuição de profissionais de enfermagem, cobrando medidas para o aprimoramento profissional e mostrando que o ensino de enfermagem estava muito longe de atender ao mínimo exigido pela população do país (Brasil, 1974).

O referido Parecer coloca, ainda, que a política do CFE quanto ao assunto era de estimu- 
lar e dirigir o aprimoramento do curso auxiliar de enfermagem, mas que havia necessidade de medidas mais proativas para a solução desta situação. Desta maneira, era acrescentado o "curso intensivo" de auxiliar de enfermagem em regime experimental, com exigência de certificado de conclusão da $4^{\mathrm{a}}$ série do ginasial para matrícula, com idade mínima de 18 anos. O curso teria período letivo único de 11 meses, com carga-horária mínima de 1.080 horas, em tempo integral e com a ministração exclusiva das disciplinas específicas (Brasil, 1974).

No Estado de São Paulo, foi a Deliberação CEE n 07/70 que instituiu o curso, nos moldes do Parecer acima citado, com a condição do mesmo ser aberto junto aos estabelecimentos mantenedores de cursos de Enfermagem. No teor desta deliberação ainda é colocada como condição para abertura de novas classes de cursos intensivos após 1973 a aprovação pelo CEE (Monteiro, 1979).

A LDB no 5.692/71 reformulou o ensino de $1^{\circ}$ e $2^{\circ}$ graus causando a profissionalização universal e compulsória do ensino secundário. De acordo com esta legislação o currículo pleno deveria conter uma parte de educação geral e outra de formação especial, focada em aquisição de aptidões e conhecimentos para o trabalho Esta legislação fixa o objetivo geral da educação de $1^{\circ}$ e $2^{\circ}$ graus um propósito: "proporcionar ao educando a formação necessária ao desenvolvimento de suas potencialidades como elemento de autorrealização, qualificação para o trabalho e preparo para o exercício consciente da cidadania." Portanto, no que concerne à escola, prover conteúdo e métodos que possibilitem, além da cultura geral básica, uma real educação para o trabalho e, de outro lado, formas de relacionamento humano em seus aspectos autoritários e inibitórios (Oguisso, 2002; Romanelli, 1995).
O CFE era incumbido de fixar as matérias do núcleo comum para cada nível limitando-se, no entanto, à definição dos seus objetivos e à sua amplitude. Os CEEs ficariam responsáveis de relacionar as disciplinas que comporiam a parte diversificada dos currículos. Desta maneira, com o Parecer do CFE no 853/71 e a Resolução no 08/71, fixou-se o núcleo comum para todos os níveis no território nacional. Este mesmo Conselho fixou um mínimo a ser exigido na parte diversificada em cada habilitação profissional de $2^{\circ}$ grau, através do Parecer no 45/72 (Romanelli, 1995).

Apesar das legislações acima aprovadas, em 1976 foi aprovado Parecer no 3.814/76 do CFE sobre as habilitações profissionais na área da saúde, estabelecendo inclusive modelo de currículos mínimos, que deu origem às Resoluções nos 07/77 e 08/77. Através da Resolução do CFE no 07/77, de 18 de abril de 1977, manteve-se o mínimo de matérias para a formação especial que havia sido ditado no Parecer no 3.814/76, além de fixar um mínimo de 2.760 horas para habilitação de técnico em enfermagem (com 1.100 horas reservadas à parte de educação geral e 1.660 horas à parte de formação especial, destas sendo 600 horas para estágio) (Brasil, 1974).

A resolução no 08/77 permitia a formação do auxiliar de enfermagem a título transitório e emergencial ao nível de $1^{\circ}$ grau, tanto no ensino regular quanto supletivo. Para o Estado de São Paulo a regulação das normas para a formação do técnico e auxiliar de enfermagem se deu com o Parecer do CEE no 25/77, onde era estabelecida a habilitação de técnico de enfermagem com duração mínima de 2.900 horas (1.200 horas reservadas à educação geral e 1.700 horas para a parte de formação especial, das quais pelo menos 800 horas eram destinadas a estágios) e a habilitação parcial 


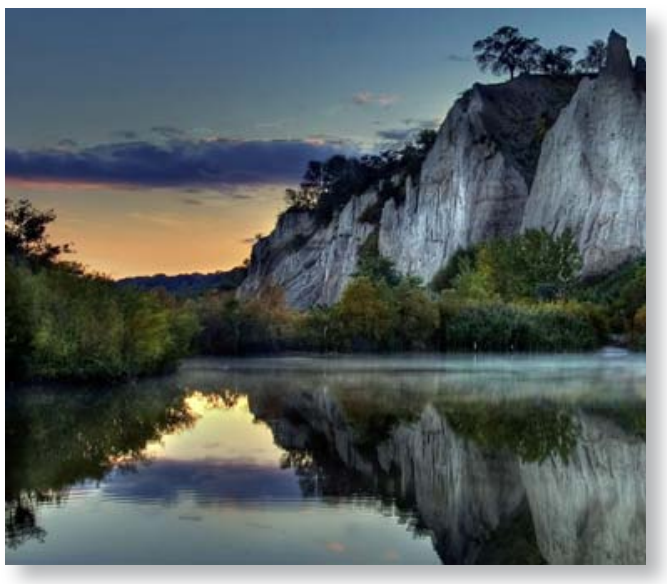

de auxiliar de enfermagem com duração mínima de 2.200 horas (1.090 horas reservadas à educação geral e 1.110 horas para a parte de formação especial, das quais pelos menos 600 horas destinadas a estágios). Para os cursos supletivos eram ministradas as cargas-horárias da formação especial (Monteiro, 2009; Brasil, 1974; Oguisso, 2002).

Através da Lei no 7.044, de 18 de outubro de 1982, que alterava os dispositivos da LDB $n^{\circ} 5.692 / 71$ referentes à profissionalização do ensino de $2^{\circ}$ grau, tornava-se facultativa a profissionalização nesta modalidade de ensino. Portanto, nesta legislação é uma opção do estabelecimento de ensino a formação profissionalizante, direcionada para o trabalho. Assim, para o ensino em enfermagem de $2^{\circ}$ grau, não houve mudanças; mas marca o fim do período histórico em que a o foco do ensino em nível nacional era a formação profissional (Santos, 1997).

$\mathrm{Na}$ coleta de dados junto à ABEn/SP foi localizado o documento intitulado "Padrões de Atribuições do Pessoal de Enfermagem", datado de 16 de julho de 1972, e emitido pelo Departamento de Recursos Humanos para a Saúde (DRHUS). O documento mencionado explicitava que aquele Departamento, criado em 1970, no âmbito do Instituto Presidente
Castello Branco como órgão da Fundação Instituto Oswaldo Cruz, do Ministério da Saúde, tinha a preocupação de definir estruturas ocupacionais, em diferentes áreas da saúde, e se propunha a estabelecer perfis das atribuições inerentes a cada nível funcional de ocupações e profissões. Neste documento, ainda, são descritos os padrões de atribuições e exemplos de tarefas típicas dos enfermeiros, técnicos de enfermagem, auxiliares de enfermagem, visitadora sanitária e atendente de enfermagem.

Através deste documento, podemos observar certa preocupação governamental em reforçar as diferenças entre os diversos níveis de enfermagem, e de fazer o mesmo com outras profissões que possuíam níveis auxiliares, como a Nutrição, Odontologia, entre outras. O documento referido foi elaborado por enfermeiras do Ministério da Saúde, do Ministério da Educação e Cultura (MEC), do INAMPS, da Secretaria de Saúde do Estado da Guanabara e da ABEn - Seção Guanabara.

Quanto ao contexto político da época, o pensamento dos governantes e sociedade em geral para com a enfermagem na década de 60 era o aumento no quantitativo do pessoal de enfermagem, para atuar no crescente número de hospitais que surgiam. Nesta década eram vividos os anos de Guerra Fria, num mundo bipolar divido entre as potências Estados Unidos e União Soviética. O presidente Jânio da Silva Quadros assumiu o governo do país em 1961, iniciando vínculos comerciais e diplomáticos cada vez mais extensos com a União Soviética, desagradando os americanos e setores políticos brasileiros. Em agosto de 1961, o presidente renunciou ao cargo, como manobra política, que não comoveu a população. Assumiu a Presidência do Brasil o vice-presidente, João Goulart, apesar da pressão dos militares para novas eleições (Ghiraldelli, 1991). 
Durante o governo de João Goulart, de 1961 a 1964, os Estados Unidos passaram a desconfiar das supostas aproximações de alguns segmentos sociais brasileiros de ideais comunistas. Dado o anúncio de uma política de reforma agrária, além do temor dos americanos e de uma parcela da elite mais conservadora da sociedade brasileira (como os militares e empresários), via-se o risco do controle das multinacionais pelo governo e de uma política de proteção à classe operária. Desta maneira, houve o golpe militar em 01 de abril de 1964 orquestrado pela burguesia dominante e executado pelos militares (Ghiraldelli, 1991; Fausto, 1995; Romanelli, 1995).

$\mathrm{Na}$ esfera econômica, a industrialização brasileira seguiu um modelo concentrador de renda, que se deu a partir de um processo de modernização introduzido pela modificação dos padrões de consumo de uma camada restrita da população. O Estado era obrigado a se posicionar favorável à sustentação de uma camada social com poder aquisitivo para consumo (classes altas e médias), enquanto a classe trabalhadora convivia com o arrocho salarial, mantendo o país com mão de obra barata (Romanelli, 1995). Desta maneira o desenvolvimento do Brasil dependeu de uma série de condições políticas e sociais para que a economia se expandisse da maneira planejada. Portanto foi necessário um reforço do poder executivo, aumentando o controle feito pelo Conselho de Segurança Nacional (CSN), a centralização da administração pública, coibindo quaisquer manifestos ou protestos em nível nacional. Nessa perspectiva, ainda, cabe pontuar que a compartimentalização da produção e do trabalho, em qualquer âmbito, eliminou ou diminuiu os "perigos" da integração social dos trabalhadores e visão crítica do conjunto do sistema produtivo (Romanelli, 1995).
No final da década de 60 o Brasil vivia o auge da ditadura, em meio ao decreto do Ato Institucional $n^{\circ} 5$ (AI-5). Viviam-se os anos dourados do "milagre econômico", com interesse de aumentar Produto Interno Bruto (PIB) para dividi-lo, o que de fato nunca ocorreu. O mesmo milagre que significaria um endividamento brasileiro com o Fundo Monetário Internacional (FMI) em 10 anos. Nos 21 anos de governo ditatorial houve aumento importante das desigualdades sociais (Ghiraldelli, 1991; Fausto, 1995).

A ditadura militar durou 21 anos, com início em 1964 e término em 1985. Neste período a repressão, privatização do ensino, exclusão de boa parcela das classes populares do ensino elementar de boa qualidade, institucionalização do ensino profissionalizante, tecnicismo pedagógico e desmobilização do magistério através da abundante e confusa legislação educacional foram os legados da ditadura na área da educação (Ghiraldelli, 1991).

Para garantir apoio da sociedade em geral no período pós-golpe, era necessário que além da força militar houvesse base ideológica nesta "revolução", para evitar um levante popular maciço. Para tal, além dos partidos oficiais foram criados os "Partidos ideológicos" que eram responsáveis pelo combate às organizações populares com visões opostas. Estes eram grupos conservadores que, no início da década de 60, conquistaram a direção intelectual e moral da sociedade, como o Instituto de Pesquisa e Estudos Sociais (IPES) e o Instituto Brasileiro de Ação Democrática (IBAD). Estas organizações eram responsáveis por cursos, boletins informativos mensais, filmes e programas de TV, incentivando a ideologia do "desenvolvimento com segurança” (Ghiraldelli, 1991).

No início da década de 60, o IPES já organizava fóruns sobre educação, formulando 
projetos de política educacional, sob a supervisão da Agency for International Development (AID). Em 1968, tornou-se imperativa sua volta pelo aumento de forças políticas da oposição (dissidentes da própria ditadura, movimento estudantil e membros do partido comunista), sendo então organizado um fórum onde publicamente foram expostos os planos governamentais. A política educacional do país ficou exposta às determinações dos técnicos americanos da AID, através dos doze acordos MEC-USAID (Ghiraldelli, 1991).

Em linhas gerais, as diretrizes pregavam a necessidade da escola atrelada ao mercado de trabalho e o ensino universitário reservado às elites. A profissionalização da escola média conteria as aspirações ao ensino superior. Este era mais um passo para alinhar o sistema educacional à ideologia econômica e política vigente. Era um passo também para uma reorganização legislativa da educação, que precisava ser coerente com os acordos firmados (Alves, 1968).

O sistema educacional deveria ser adequado ao modelo econômico desenvolvimentista, desta maneira a estratégia utilizada foi a do treinamento do pessoal docente e técnico, com aumento de recursos materiais e a reorganização do currículo, com vistas ao treinamento, no nível desejado para preencher as categorias ocupacionais das empresas em expansão, adequando assim a educação às necessidades do desenvolvimento. Portanto, se delineava um cenário em que a demanda por profissionais de nível médio crescia em ritmo mais alto que a oferta (Romanelli, 1995).

As condições de vida da população na época continuavam a piorar, pelo aumento das desigualdades e diminuição dos investimentos nas políticas sociais. O milagre econômico entra em falência em 1974, culminando com a crise do petróleo. O aumento da inflação e da dívida externa, a dependência do FMI e a diminuição do PIB foram o cenário do final da década de 70. O aumento do desemprego e dos impostos, e a desvalorização dos salários levaram a um cenário onde a maioria da população estava empobrecida pela desigualdade na distribuição de renda (Ghiraldelli, 1991; Kletemberg et al, 2011).

$\mathrm{Na}$ saúde brasileira, o enfoque curativo predominava, e estimulou a expansão da produção e consumo no complexo médico- industrial. As inovações tecnológicas na área da saúde demandaram o surgimento de novos perfis profissionais em duas áreas opostas: o profissional altamente especializado para o setor hospitalar e os profissionais de saúde coletiva para os novos programas governamentais de saúde pública. As décadas de 1970 e 1980 caracterizaram-se pelas lutas da enfermagem como categoria, cujos esforços culminaram com a Lei no 7.498, de 25 de junho de 1986, que regulamentou a prescrição e a consulta de enfermagem como atribuições do enfermeiro e a definição de atribuições para cada membro da equipe de enfermagem, além do prazo de dez anos para profissionalização dos atendentes de enfermagem (Kletemberg et al, 2011, Geovanini et al, 2002).

No final dos anos 1970, as Políticas Públicas privilegiavam a prática médica curativa, individual e especializada em detrimento das ações de caráter preventivo e de interesse coletivo. O Estado mediava o incremento do complexo médico-industrial privado que objetivava lucro. Em contraponto, as endemias assolavam o país no período de 1960 a 1989. A maior parcela das necessidades de saúde da população poderia ser atendida com atenção primária no domicílio, em consultórios e em postos de saúde: vacinas, clínica médica, pe- 
diatria e ginecologia, educação em saúde, água potável, alimentação, dentre outros (Kletemberg et al, 2011).

Na mesma época, os sistemas de saúde de países pobres e ricos são atingidos pela crise econômico-social global, submetidos às políticas econômicas de ajuste estrutural, sofrendo graves implicações sociais. Portanto, a crise da saúde no Brasil estava inserida em um fenômeno mundial (Kletemberg et al, 2011).

O Brasil e outros países elaboraram modelos alternativos para seus sistemas de saúde, com diferentes orientações, buscando a racionalização em saúde. Sendo assim, em 1980, o Ministério da Saúde organizou VII Conferência Nacional de Saúde (CNS), com a participação restrita de dirigentes da saúde pública, mas graças a fortes manifestações populares e de lutas sociais em prol da saúde, foi-se consolidando a mentalidade de saúde como um bem e não como mercadoria, o que se confirmou, posteriormente, com a criação do Sistema Único de Saúde (Kletemberg et al, 2011, Geovanini et al, 2002)

Houve estimulo à criação de Escolas de Enfermagem, (não só de graduação, mas também no ensino técnico profissionalizante) constituindo um fato perceptível nesse contexto, devido à escassez de mão de obra no mercado de trabalho. Com isso, buscou-se desenvolver as tecnologias na área hospitalar, e ampliar a porcentagem da força de trabalho especializada. O contingente de atendentes de enfermagem acompanhou essa expansão, dado o custo menor de sua força de trabalho. Somente em 1986, com a Lei do Exercício Profissional no 7.498/86, definiram-se as atribuições das categorias que constituíam a enfermagem, estando os atendentes de enfermagem excluídos como categoria profissional. (Kletemberg et al, 2011, Geovanini et al, 2002)

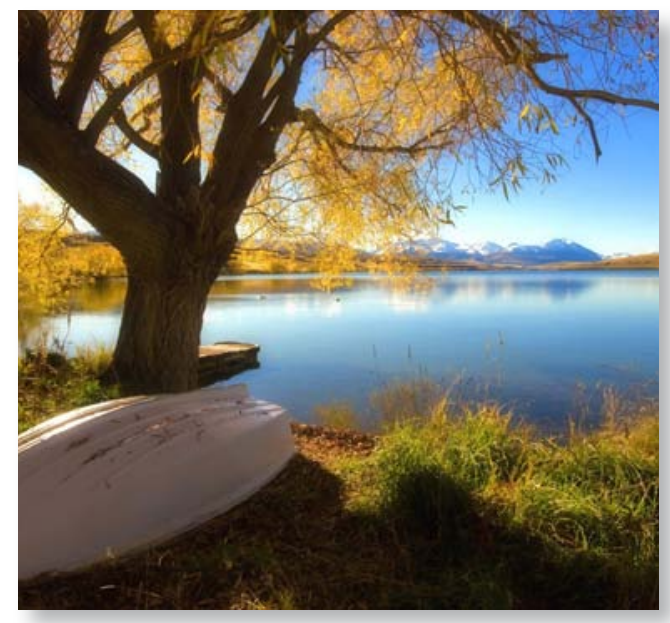

Esse complexo contexto político e econômico da história da sociedade brasileira é de extrema relevância para se compreender os meandros dos interesses que perpassam não só as questões de saúde, mas também as questões do ensino nessa área, envolvendo a formação de profissionais em diversos níveis. Dessa forma, não se pode negligenciar que tal contexto insere-se em uma conjectura política autoritária, nascedouro de uma segunda LDB, a qual influenciou, certamente, o cenário da formação dos profissionais de enfermagem em todos os níveis. Obviamente que as entidades representativas da enfermagem encontravam-se inseridas, politicamente, nesse contexto e daí a importância de se desvelar como e com que armas lidaram com as questões atinentes à formação dos profissionais.

A Associação Brasileira de Enfermagem (ABEn) é uma organização civil de direito privado sem fins lucrativos, reconhecida de utilidade pública. Em 26 de abril de 1945 foi fundada a Seção São Paulo, que teve como primeira presidente a Enfa Edith de Magalhães Fraenkel, Docente da Escola de Enfermagem da Universidade da São Paulo (EEUSP). Em 1969, após o $1^{\circ}$ Encontro de diretoras, professoras e interessados na formação do auxiliar de 
enfermagem, foi discutida a necessidade de um local para que a formação destes profissionais fosse discutida. Em 1970, foi criado o grupo regional de trabalho integrado sobre o auxiliar de enfermagem, nomeado como "Subcomissão de Educação da ABEn/SP" (pois trabalharia sob a orientação da Comissão de Educação da ABEn/SP), que tinha como finalidade “(...) estudar problemas, situações, propor soluções, dar consultas sobre a formação dos auxiliares de enfermagem." (Carvalho, 2008).

Os membros desta subcomissão eram as diretoras das Escolas de Auxiliares de Enfermagem do estado de São Paulo ou as assessoras. Através destas atas podemos ver a preocupação da ABEn/SP em assuntos relacionados aos auxiliares de enfermagem, especialmente quanto ao levantamento das escolas, padrão curricular (com ênfase sobre os estágios exigidos), estrutura administrativa e os recursos. Desta maneira, na ata da criação da subcomissão, já era citada como uma das primeiras atividades, que ocorreu no XXII Congresso Brasileiro de Enfermagem (de 20 a 25 de julho de 1971, em Manaus), que fosse solicitado à presidente Enfa Amália Corrêa de Carvalho uma reunião de diretoras de cursos auxiliares de enfermagem, tendo como uma das finalidades assistir a exposição sobre o projeto no 287/6.302 deu origem ao Parecer no 75/70 que tratava do curso intensivo de auxiliar de enfermagem. O curso intensivo de auxiliar de enfermagem era de especial interesse da ABEn pois ia de encontro à política da Instituição que acreditava na profissionalização da equipe de enfermagem, que nesta época constituía-se majoritariamente de pessoas sem preparo formal. Carvalho (2008) cita que "A inovação parece ter sido bem aceita pelos enfermeiros educadores, convencidos da comprovada necessidade de formação de pessoal de enfermagem a curto prazo."(p. 197). As atas revelam que o assunto do curso intensivo de auxiliar de enfermagem era amplamente discutido, e que, no Estado de São Paulo, o mesmo foi bem assimilado pelo sistema de ensino.

Em um ofício, com o número 09/73, enviado pela Comissão de Educação da ABEn/ SP para a Enfa Maria Rosa Sousa Pinheiro Neste documento, de valor histórico para a profissão da enfermagem, podemos observar o convite da Comissão de Educação da ABEn/ SP, na figura da enfermeira Yolanda Lindemberg Lima, para o "I Seminário Estadual sobre curso supletivo de qualificação profissional do auxiliar de enfermagem em regime intensivo", que foi realizado de 10 a 15 de junho de 1971. Através do documento referido fez-se menção ao convite enviado à Enfermeira (Enfa) Maria Rosa Sousa Pinheiro, Diretora da EEUSP, solicitando a presença da Enfa Moema G. Barbato neste evento.

Através deste ofício pode-se observar a relevância da LDB no 5.692/71 para a formação do nível médio em enfermagem. O documento acima denota a preocupação em realizar discussão do assunto com os profissionais da época, com participação de autoridades como o Secretário da Saúde e participantes da Coordenação Nacional do Programa Intensivo de Preparação de Mão de Obra (PIPMO) - Área da Saúde.

Portanto, percebe-se que essa discussão sobre a formação no curso intensivo de Auxiliar de Enfermagem, segundo as normativas da segunda LDB, de 1971, interessava à sociedade como um todo, invocando colocações e disputas sociais não só dentro da categoria da enfermagem, trazendo para o debate autoridades públicas de destaque.

Na IV Conferência Nacional de Saúde, realizada em 1967, que teve como tema principal "Recursos Humanos para as Atividades de Saúde”, a formação de pessoal de nível téc- 
nico foi um dos temas que integrou a agenda. Naquela oportunidade foram ressaltadas a responsabilidade do Ministério da Saúde na formação dos profissionais de Saúde e do pessoal de nível médio e auxiliar. As entidades governamentais preocupadas com o pessoal despreparado do setor de Saúde, firmaram, na década de 70, o Acordo para desenvolvimento de Recursos Humanos entre o Brasil e a Organização Pan-Americana de Saúde (OPAS), no qual foram criadas as estratégias que apoiavam o desenvolvimento de processos de qualificação profissional. O Programa de Preparação Estratégica para Pessoal de Saúde (PPREPS), foi criado com a finalidade de realizar intervenções em momentos históricos do setor de saúde no país no âmbito da educação (Silva, 2002; Costa, 2003; Kletemberg et al, 2011).

Assim, o PPREPS testava estratégias e modelos que geravam qualificação profissional garantindo o acesso da população a serviços de Saúde livre de riscos e a cidadania de um contingente de trabalhadores excluídos do sistema educacional. Este iniciou suas atividades em 1976, visando a melhoria da qualidade da formação de pessoal de Saúde, levando em conta as necessidades e possibilidades dos serviços, através da progressiva integração de capacitação na realidade do Sistema de Saúde (Silva, 2002;Costa, 2003).

No documento "Metas para o novo decênio da saúde", emitido 10 de outubro de 1974, podemos ver reafirmada a necessidade de aumentar a produção de recursos humanos em enfermagem, sobretudo da equipe "que se ocupa do cuidado direto às pessoas", que seria a equipe de nível médio em enfermagem. Este documento é uma resolução, da $11^{\text {a }}$ reunião plenária, do XIX Conferência Sanitária Pan-americana.
Este documento corrobora com a necessidade do aumento de pessoal de enfermagem, especialmente em cargos de assistência direta ao paciente, que seria exatamente o pessoal de nível médio de enfermagem, foco deste estudo.

O Programa de Formação em Larga Escala de pessoal de Nível Médio e Elementar para os serviços básicos de saúde (PLE), não só configurou como uma política pública, mas também como estratégia de formação, experiência pedagógica, movimento ou ideia visando qualificar uma força de trabalho empregada no setor saúde, propondo a democratização do sistema de saúde, bem como mudanças na prática profissional dos trabalhadores deste setor. O PLE surgiu em 1981, fruto do processo de reformulação dos serviços de saúde que visavam a extensão de cobertura. (Bassinello, Bagnatto, 2009).

Foram localizados, junto à $\mathrm{ABEn} / \mathrm{SP}$, documento da Secretaria do Estado de Saúde, de São Paulo, que mencionam o referido PLE, descrevendo as características do projeto.

Em maio de 1950 era formada a primeira Associação de auxiliares de enfermagem, sob o nome de Associação Nacional de Auxiliares de Enfermagem (ANAE), com sede no Rio de Janeiro. A palavra Associação foi logo depois modificada para União, formando a sigla utilizada UNAE. A UNAE e a ABEn mantinham contato, sendo que em determinada ocasião foi proposto que os auxiliares pudessem se associar à ABEn, fato que nunca ocorreu devido ao Estatuto da entidade (Carvalho, 2008).

Através da série Documenta foram achados três pareceres de reivindicações da UNAE junto ao CFE, no 26/71, no 169/71 e no 778/72. Os três se relacionam ao mesmo assunto, que seria o curso intensivo de auxiliares de enfermagem. A UNAE se posicionava contra a criação dos cursos intensivos de auxiliares de 
enfermagem, reivindicando que a carga-horária era insuficiente e que os alunos tinham uma carga-horária semanal muito elevada, levando-se em consideração o curso normal. Quanto ao primeiro ponto, o curso intensivo de auxiliar de enfermagem tem a mesma carga-horária dos cursos normais, porém sem a parte das disciplinas obrigatórias, apresentando o certificado de conclusão do ciclo ginasial. Portanto, este ponto não era realmente um ponto de discussão. Sobre a distribuição de carga-horária semanal, o curso deveria ser dado em onze meses, à escolha das escolas a distribuição de carga-horária diária. Era contra-argumentado que o público alvo dos cursos intensivos seriam pessoas já engajadas no mercado de trabalho e com pouco tempo disponível para realização do curso. Outro ponto discutido pelo CFE, era a grande necessidade de que fosse formado pessoal de enfermagem qualificado, em um cenário da década de 70, com cuidado prestado por pessoas sem qualificação.

\section{DISCUSSÃO}

Após a análise de cada documento, tanto interna como externamente, passou-se à exploração documental, indagando-se sobre o contexto da formação documental: quem teria elaborado cada documento e o cenário político da sua construção. Assim, a seleção do corpus documental do presente estudo exigiu análises e comparações entre legislações que antecederam ou que sucederam à LDB no 5.692/71, objeto dessa investigação.

Na presente investigação, na Lei de Diretrizes e Bases da Educação Nacional no 5.692, de 12 de agosto de 1971, houve o interesse de se discutir a formação profissionalizante nas escolas de enfermagem em nível médio, bem como o contexto da sociedade brasileira da época, bem como circunstâncias e vicissitudes históricas, da criação dessa legislação, além das aquisições e desdobramentos nesse importante nível da formação em enfermagem.

A LDB no 5.692/71 demorou somente um ano para ser promulgada. Muito diferente foi a situação da LDB anterior, no 4.024/61, que foi promulgada somente treze anos após o início da discussão do projeto. Isso é compreensível se contextualizamos a LDB de 1971 no entorno da Ditadura Militar, pois de acordo com Ghiraldelli (1991), esta LDB de 1971 implementou a profissionalização para o ensino secundário. Em junho de 1970, iniciada a discussão sobre o projeto de lei que originaria a $\mathrm{LDB}$ de 71 , teve como cenário político o AI-5 (mecanismo político de repressão) e a ideologia do "milagre econômico", segundo a qual o crescimento econômico do país resultaria em benefícios para a coletividade social, o que de fato não aconteceu, pois a ditadura militar brasileira (como todas as ditaduras latino-americanas) propugnava pela concentração de renda, da defesa do interesse do capital e da propriedade privada.

A ideia da promulgação da LDB de 71, bem mais rapidamente do que a anterior, justifica-se, desse modo, pelo fato da repressão às lutas sociais que tentavam forjar uma oposição ao governo militar da época. Nessa direção, ainda, o papel escolar era atrelado ao mercado de trabalho e o ensino universitário reservado às elites. A profissionalização da escola média conteria as aspirações ao ensino superior, sendo este mais um passo para alinhar o sistema educacional à ideologia econômica e política vigente. Era um passo também para uma reorganização legislativa da educação, que precisava ser coerente com os acordos firmados. Kletemberg et al (2011) também afirma que os documentos que definiram a política educa- 
cional brasileira tinham suas vigas mestras nos acordos MEC-USAID, que influenciaram em todas as áreas da educação brasileira.

Percebemos nítido alinhamento do sistema educacional aos propósitos internacionais, especialmente americanos. Assim, a reorganização do currículo para a formação profissional tinha em vista esse propósito de treinamento no nível desejado para ampliar as categorias ocupacionais das empresas em expansão, adequando-se a educação às necessidades do desenvolvimento, favorecendo o capital estrangeiro (Romanelli, 1995).

Ainda segundo este autor, naquele cenário sócio-econômico da década de 70 , havia um descompasso entre a demanda por profissionais de nível médio e a oferta desse tipo de agente. A política governamental, que ao mesmo tempo incentivava a profissionalização por intermédio da formação de mão de obra em nível profissionalizante, foi influenciada pela ideia da formação de mão de obra mais barata para as empresas como incentivo, mormente naquele contexto do chamado "milagre econômico". Ou seja, visava-se a formação mais rápida de mão de obra, em grande escala, e que não representasse um ônus econômico maior para as ditas empresas, a fim de atraí-las.

Como revelam os resultados, referentes ao contexto da enfermagem no início da década de 1970, 70\% do pessoal de enfermagem contratado nos serviços de saúde não tinha formação. (Oguisso, 2002) Desta maneira, ao longo desta década houveram várias tentativas de profissionalizar o pessoal de enfermagem. Uma destas tentativas foi o Programa de Formação em Larga Escala de pessoal de Nível Médio e Elementar para os serviços básicos de saúde (PLE). Este, não só se consolidou como uma política pública, mas também uma estratégia de formação, visando qualificar a força de trabalho empregada no setor saúde (Bassinello, Bagnatto, 2009).

As condições para a realização do referido projeto seriam o não afastamento do trabalhador de seu ambiente de trabalho. Essa política era compreensível, pois se a mão de obra era escassa, essa deveria ser explorada duplamente, sendo exigida maior qualificação por um lado, além de assegurar continuidade do trabalho por outro. A LDB n ${ }^{\circ} 5.692 / 71$ e a Resolução do CEE no 23/83 ampararam este projeto, em consonância com o pensamento de Gryshek et al (2002), alinhado às diretrizes da OPAS para o ensino em nível médio em enfermagem.

As diretrizes mencionadas foram firmadas por entidades governamentais, como o Ministério da Saúde, cujo interesse era o desenvolvimento do pessoal do setor de Saúde. Para superar a inadequação do preparo do pessoal de nível médio em enfermagem, firmou-se o Acordo para desenvolvimento de Recursos Humanos entre o Brasil e a OPAS, no qual foram propostas estratégias que apoiavam o processo de qualificação profissional. Neste âmbito institui-se o Programa de Preparação Estratégica para Pessoal de Saúde (PPREPS), que corroborava a qualificação da mão de obra em nível médio de enfermagem (Silva et al, 2002; Costa, 2003).

Ainda no bojo destas políticas de qualificação de mão de obra em enfermagem, o documento "Metas para o novo decênio da saúde", datado de 10 de outubro de 1974, reafirmou a necessidade de aumentar a produção de recursos humanos, sobretudo da equipe "que se ocupa do cuidado direto às pessoas", que seria a equipe de nível médio em enfermagem.

Os projetos supracitados (tanto o PREPPS quanto o PLE) reforçavam a necessidade da qualificação de mão de obra, já que o contin- 
gente de enfermagem na década de 1970 era majoritariamente sem formação específica, pois havia uma discussão no bojo da sociedade sobre o direito a uma assistência de enfermagem que proporcionasse benefícios à população e a isenção de riscos (Oguisso, 2002).

A participação da ABEn nas questões políticas da formação dos profissionais de nível médio em enfermagem é histórica. Esta entidade foi e continua sendo pioneira nas propostas educativas de formação de pessoal de enfermagem.

Se na década de 60 a assistência médica individualizada prestada pela previdência, direta ou indiretamente, passava, evidentemente, por um momento de grande expansão, nas décadas seguintes não foi diferente, exigindo da área da enfermagem maior participação nesse "jogo histórico-social”. Fato este que "exigia da enfermagem maior participação frente a questões de saúde, quando, então, surgiu a necessidade de maior disciplinamento do trabalho" (Monteiro, 2009, p. 96). Nesse sentido, a ABEn, como entidade representativa dos interesses políticos e ideológicos dos profissionais da área, avocou para si sua responsabilidade histórica, no sentido de continuar participando do debate sobre as questões da formação dos recursos humanos na enfermagem.

Os resultados obtidos e apresentados anteriormente denotam o especial interesse da ABEn na formação de nível médio em enfermagem, pois quando analisadas as Atas da Subcomissão de Educação da ABEn/SP, evidenciaram-se lutas dos membros desta entidade para que fossem discutidos os termos do curso intensivo de auxiliares de enfermagem. Como ditos nos resultado este curso propunha a redução de 18 meses para 11 meses, sendo ministrado o conteúdo de formação profissional, como já citado anteriormente (Carvalho, 2008).

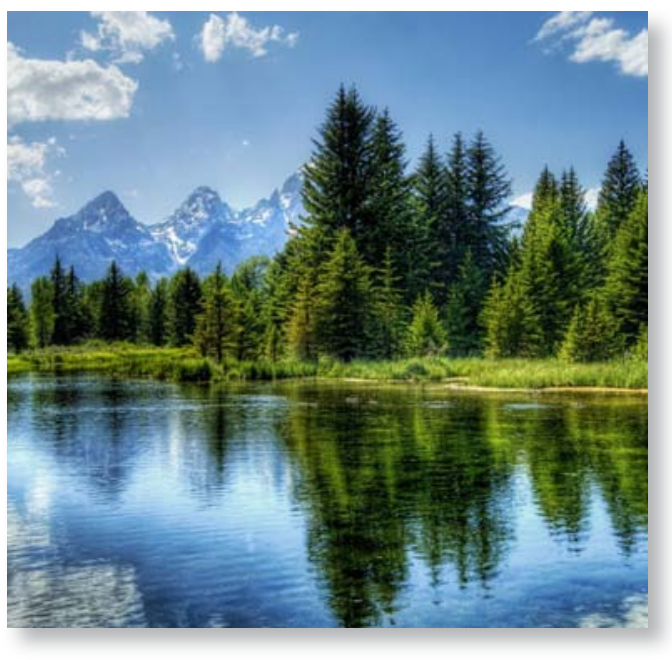

A LDB no 5.692/71 foi a legislação que baseou o ensino no país por quase três décadas, até a promulgação da LDB atual ou vigente. A LDB de 1971 trouxe ao sistema de ensino nacional como principal característica a profissionalização universal. O currículo seria regulado em instância regional pelo $\mathrm{CEE}$, e teria como normas nacionais o que estivesse regulamentado pelo CFE.

No tocante à discussão da educação de nível profissionalizante em enfermagem, na $\mathrm{ABEn} / \mathrm{SP}$, particularmente, se constituiu um grupo para discutir estas questões, a partir de 1994, chamado GIEMEn. No regimento deste discutiam-se suas finalidades destacando-se o intercâmbio entre instituições formadoras de profissionais de enfermagem em nível médio. Para tanto este grupo propunha a realização de fóruns de discussões permanentes do ensino neste nível (Caverni, Sanna, 2002, p.263).

Em síntese, os desdobramentos e impactos da LDB no 5.692/71 revelam a forte participação política dos profissionais da enfermagem, guiados pelas normativas da ABEn, no campo da educação profissionalizante em enfermagem. Esta participação não se dá somente pelo discurso dos enfermeiros por intermédio da "voz autorizada" da ABEn, mas também, de 
outros coletivos como GIEMEn e União Nacional dos Auxiliares de Enfermagem (UNAE), cujo escopo maior era congregar as discussões sobre a formação e o exercício de auxiliares de enfermagem.

\section{CONSIDERAÇÕES FINAIS}

Confrontando-se com a LDB n ${ }^{\circ} 5.692 / 71$ as legislações de ensino antecedentes, percebem-se nuances e diferenças relativas ao objetivo geral desta última que consistia em proporcionar ao educando a formação necessária ao desenvolvimento de suas potencialidades como elemento de auto-realização, qualificação para o trabalho e preparo para o exercício consciente da cidadania.

Como fora discutido antes, questiona-se esta proposição da formação para o "exercício consciente da cidadania”, pois o cenário político da década de 70 era de um estado de repressão política, o que certamente refletia na prática do ensino em todos os níveis, inclusive no profissionalizante.

No que diz respeito ao desenvolvimento da profissão como um todo, tanto a LDB $n^{\circ}$ $4.024 / 61$, quanto a LDB no 5.692/71, contribuíram, sim, para as discussões sobre o currículo mínimo de nível médio em enfermagem. Estas legislações diretivas da educação nacional, certamente, foram importantes para a regulamentação do ensino.

A LDB no 5.692/71, portanto, é um documento que nos informa quem eram os sujeitos que detinham a legitimação para produzi-la, representando um dos jogos de forças presentes nas relações sociais. Esta LDB corrobora o sistema político da época, cuja ideologia mascarava interesses econômicos e ideológicos ditatoriais.

O sentido dos estudos das legislações do ensino nacional, mormente da LDB $n^{\circ}$
$5.692 / 71$, solidifica mais e mais a enfermagem como uma das profissões mais necessárias socialmente, seja pelas necessidades sociais em saúde crescentes naquela época, seja no contexto atual. A enfermagem continua contribuindo para as estratégias de melhoria da saúde da pessoa humana e da coletividade.

Apesar das questões do ensino da enfermagem não se encontrarem explicitadas no texto da LDB no 5.692/71, os resultados deste trabalho revelaram que ela influenciou outras legislações sobre o ensino profissionalizante desta área, e, consequentemente, a formação dos profissionais.

\section{REFERÊNCIAS}

- Alves, M.A. (1968) Beabá dos MEC-USAID Ed Gernasa Rio de Janeiro.

- Bassinello G.A.H., Bagnato M.H.S. (2009) Os primórdios do Projeto Larga Escala: é tempo de rememorar. Rev. Bras. Enf. 62(4): 620-626

- Brasil. Ministério da Saúde. Fundação serviço de Saúde Pública (1974). Enfermagem: Legislação e assuntos correlatos. . $3^{\text {a }} \mathrm{Ed}$. Vol I, II e III, Rio de Janeiro.

- Carvalho A.C.D. (2008) Associação Brasileira de Enfermagem - 1926/1976: Documentário: 2a Ed , Brasília: Associação Brasileira de Enfermagem.

- Caverni L.M.R. (2005) Curso Técnico de Enfermagem: uma trajetória histórica e legal - 1948 a 1973. [dissertação] São Paulo (SP): Escola de Enfermagem da USP.

- Chartier R. (1990) A história cultural. Entre práticas e representações. Trad. Galhado MM. Rio de Janeiro: Bertrand Brasil.

- Chizzotti A. (2010) Pesquisa qualitativa em ciências humanas e sociais. $3^{\text {a }}$ Ed. Petrópolis: Editora Vozes.

- Costa M.F.B.N.A.C. (2003) A inserção do técnico de Enfermagem no mercado de trabalho da Baixada santista: fatores dificultadores e facilitadores. Dissertação. São Paulo.

- Dantas R.A.S.; Aguilar, O.M. (1999) O ensino médio e o exercício profissional no contexto da Enfermagem Bra- 
sileira. Rev. Latino-am. Enf. 7(2):25-32.

- Fausto B. (1995) História do Brasil. São Paulo: Ed da Universidade de São Paulo.

- Ghiraldelli P.J. (1991) História da Educação. São Paulo: Ed Cortez.

- Kletemberg D.F., Vieira M., Bertoncini J.H., Padilha M.I., Borenstein M.S. (2011) O Fascínio da ciência na área de saúde 1960-1990. In: Enfermagem: História de uma profissão. Padilha M.I, Borenstein M.S., Santos I (Orgs). Difusão editora. São Caetano do Sul.

- Lima E.C., Appolinário R.S. (2011) A educação profissionalizante em enfermagem no Brasil: desafios e perspectivas. Rev. Enferm .Universidade do Estado do Rio de Janeiro 19(2):311-6

- Monteiro M.B.L. (1979) Secretaria de Educação do Estado de São Paulo, Coordenadoria de Estudos e Normas Pedagógicas. Estrutura e funcionamento dos cursos supletivos de qualificação profissional na área de enfermagem.

- Monteiro, B.A. (2010) Diretrizes e Bases da Educação Nacional e escolas de enfermagem da década de 1960: uma visão histórica. [dissertação] São Paulo (SP): Escola de Enfermagem da Universidade de São paulo

- Oguisso T. (1977) Considerações sobre a legislação do ensino e do exercício do técnico de enfermagem e do auxiliar de enfermagem. Rev Bras Enf. 30: 168-174
- Oguisso, T. (2002) História da legislação do ensino médio profissional de enfermagem. Rev Paul Enf. 21(1): 160-170

- Porto F., Freitas G.F., González J.S. (2009) Fontes históricas e ético-legais: possibilidades e inovações. Rev Cultura de los Cuidados; Universidad de Alicante (España), Año XIII; N. 25: 46-53.

- Revel, J. Microanálise e construção do social. In: Revel J. Coord. (1998) Jogos de escala: a experiência da microanálise. Rio de Janeiro: Editora Fundação Getúlio Vargas, p.15-38

- Romanelli O.O. (1995) História da educação no Brasil 1930/1973. 17a Ed, Petrópolis. Rio de Janeiro, Ed Vozes.

- Santos E.F., Santos E.B., Santana G.O., Assis M.F., Meneses, R.O. (1997) Legislação em enfermagem: Atos normativos do exercício e do ensino. São Paulo. Editora Atheneu.

- Santos M.R., Trezza M.C.S.F., Candiotti Z.M.C., Leite J.L. (2002) Circunstâncias de oficialização do curso de auxiliar de enfermagem no Brasil: estudando as entrelinhas de Lei 775/49.Rev Latino-am Enf. 10(4): 561-570.

- Silva J.A. (2002) Estratégias de Qualificação e inserção de trabalhadores de nível médio na área da saúde. In Negri B., Faria R., Viana A.L.D. organizadores. Recursos Humanos em saúde: política, desenvolvimento e mercado de trabalho. Campinas. Ed. Da Unicam. 